\title{
Adaptation and Validation of the DUNDEE Ready Education Environment Measure (DREEM) for a Practice Teaching Program
}

\author{
Josephine Pelingon \\ Leyte Normal University Tacloban City, Leyte, 6500, Philippines
}

\begin{abstract}
The study examined the psychometric properties of the DUNDEE Ready Education Environment Measure (DREEM) in the context of a practice teaching program environment. The DREEM has been validated in many countries and is a widely recognized tool to measure students' perception of their learning environment in medical and allied health education programs. Data for this study come from 316 fourth year teacher education students who have already finished their practice teaching program. Principal components analysis (PCA) with Varimax rotation was used to examine the underlying component structure of the items of the instrument. PCA results indicated the presence of a five-component structure which supports other validation studies. However, component loadings of the items were not consistent with the original DREEM resulting to a shortened version. The shortened DREEM has a Cronbach alpha of 0.83 , indicating a high internal consistency of its items. The adapted DREEM is a valid and reliable instrument for measuring practice teachers' perception of their learning environment. The instrument will be called Practice Teacher Education Environment Measure (PTEEM).
\end{abstract}

Keywords: Educational environment, student teaching, adaptation, validation, principal component analysis DOI: $10.7176 / \mathrm{JEP} / 10-9-04$

Publication date:March $31^{\text {st }} 2019$

\section{Introduction}

The culminating phase of the teacher education curriculum in the Philippines is the teaching internship program. Students enrolled in the program are called student teachers or practice teachers. Perhaps this is the most challenging and rewarding part of the teacher education curriculum because during this phase, practice teachers are able to demonstrate in their respective classrooms the various concepts, theories and procedures learned about the art of teaching. It is avenue where practice teachers under the guidance and leadership of cooperating teachers are expected to develop the instructional competence expected of them before they graduate from the program. Acquiring instructional competence is influenced by various school and personal factors, one of which is a positive learning environment. Findings from various studies demonstrate that a positive teaching and learning environment significantly impact academic competence (Usaini, et al., 2015; Shamaki, T. A. 2015; Thapa et al., 2013; Dahar et al., 2009; Kamaruddin, et al., 2009; Lizzio, et al., 2002). Hence, it is imperative that a positive learning environment is provided to preservice teachers during their practice teaching program in order for them to acquire instructional competence.

Just like any other academic program, the success of the practice teaching program can be gauged through an evaluation process. How practice teachers feel about their learning environment both in-campus and off-campus shifts is an important source of information that can be factored in during the evaluation process. However, as practiced in some teacher training institutions in the country, assessment is an activity done mainly by the cooperating or supervising teachers and is mostly centered on how practice teachers perform their role as future teachers. Students do not have a voice especially on the kind of learning environment they are exposed to in their practice teaching program. A literature review on studies about student teachers' perception of their learning environment reveals that no such studies have been conducted in the Philippines. If ever studies are done, mostly, these are on competencies and problems met while doing their practice teaching (Ambag, 2015; Ganal et al. 2016). Perhaps one reason that can be attributed to this scenario is the lack of instrument for assessing the learning environment of practice teaching program in teacher training institutions.

An instrument that measures the learning environment of undergraduate medical students is the Dundee Ready Education Environment Measure (DREEM). Developed by Roff et al. in 1997, the DREEM has been translated to many different languages (Mogre, V., \& Amalba, A. 2016; Riga et al., 2015; Miles et al., 2012; Yusoff, 2012; and Dimoliatis et al., 2010). Validity studies using exploratory and confirmatory analyses have also been carried out in many countries (Khan et al. 2011; Vaughan et al. 2014; Yusoff, 2012; Hammond et al. 2012; Mogre \& Amalba, 2016; Leman 2017; Jakobson et al. 2011; Schonrock-Adema, 2009). Results of these studies show overall reliability coefficients ranging from $0.88-0.94$ indicating internal consistency reliability as high as the original instrument (Cronbach $\propto=0.91$ ) even if respondents are of different nationalities. However, each of these studies did not support the five-factor structure of the original DREEM instrument.

The DREEM has also been extensively used in other countries for assessing the learning environment of 
undergraduate students in other allied health programs (Patil et al, 2016; Bakhshialiabad, et al, 2015: Koopayehzadeh, 2014; Khursheed, I., \& Baig, L., 2014; Hamid et al, 2013, Brown et al. 2011; Aghamolaei \& Fazal, 2010; and Edgren et al, 2010). In the Philippines, two published studies were found utilizing the DREEM for determining the perceptions of students concerning their learning environment. Barcelo (2016) compared the perception of the academic learning environment between medical laboratory science students and nursing students at Saint Louis University, Baguio City, Philippines. Overall result show that the perceptions of medical laboratory science students on their academic learning environment were not significantly different from those of the nursing students. Bay Jr. B. E. \& Subido, H. (2014) adopted the DREEM to evaluate the learning environment of the College of Dentistry in Lyceum of the Philippines University. The study found that dental students perceived their academic environment as conducive to learning. However, both studies did not present any validation process done to the instrument before it was used for data gathering.

Studies about adoption and adaptation of the DREEM in non-medical curricular programs are scarce. Atapattu et al, (2015) used a modified version of the DREEM questionnaire to assess the learning environment of students enrolled in the Bachelor Science (Agriculture) degree program in Sri Lanka while Riga (2015) adopted the Greek version of the scale to measure the practical training environment of students enrolled in Educational Studies and Early Childhood Education at the University of Patras in Greece. To the author's knowledge, no study has been conducted about validating the DREEM instrument in the Philippines, hence, this study. The aim of this study is to evaluate the psychometric properties the DREEM as a measure for assessing the learning environment of the practice teaching program of the teacher education curriculum in a Philippine university.

\subsection{Methods}

\subsection{Instrument}

The Dundee Ready Education Environment Measure (DREEM) consists of 50 statements, 41 of which are positive and nine are negative. Each item is rated using a five-point Likert-type scale ranging from 0 -strongly disagree to 5-strongly agree. The instrument contains five subscales namely; perceptions of learning, perceptions of teachers, academic self-perceptions, perceptions of atmosphere, and social self-perceptions. Although the authors claim that the DREEM is culture-free, changing some words and phrases in the original items that are not in the context of practice teaching is necessary. For instance, the words teaching, teachers, patients, and department were replaced with practice teaching, cooperating teachers, practice teachers and cooperating school, respectively. A team composed of five cooperating teachers evaluated the items that were modified to ensure its relevance and appropriateness for the context of the study. Thirty practice teachers were asked to answer the modified item pool and also to give their comments and suggestions to ensure the meaning and clarity of each statement. The instrument was further modified by incorporating all the comments and suggestions from the cooperating teachers and practice teachers. The final form of the instrument was pilot tested to a group of practice teachers who were not part of the study. The pilot test revealed an internal consistency reliability of 0.83 which is considered to be adequate (Nunnally, 1978). Moreover, the researcher was granted permission by the authors to adapt and validate their instrument in this study.

\subsection{Sample}

Three hundred ninety-eight practice teachers chosen randomly from two batches of the Bachelor of Elementary Education and Bachelor of Secondary Education of Leyte Normal University in the Philippines anonymously completed the modified DREEM questionnaire. Permission from the practice teaching supervisors was sought before the administration of the questionnaire. The researcher conducted an orientation with the practice teachers on the purpose of the research and how the questionnaire will be answered before they completed the scale. Participation in the study was voluntary. The scale was administered after the students have already completed both in-campus and off-campus shifts of their practice teaching program.

\subsection{Data Analysis}

Data for this study were subjected to Principal Component Analysis (PCA). This is a statistical technique used to reduce the dimensionality of uncorrelated variables (in this case, items in the DREEM instrument) into a smaller set retaining most of the information of the original data set (Dunteman, 1989). Aside from reducing dimensionality, PCA is also used to modify or shorten an instrument and to explore whether the structure of the original version is supported by a sample data set (Kellows, 2007). The analysis followed the general guidelines for principal component analysis. Before performing PCA, suitability of data for analysis and sampling adequacy was determined through the Kaiser-Meyer-Olkin (KMO) measure of Sampling Adequacy. Field (2005) states that KMO values between 0.5 and 0.7 are mediocre, values between 0.7 and 0.8 are good, values between 0.8 and 0.9 are great and values above 0.9 are superb. Bartlett's test of sphericity was performed to assess whether the data set is suitable for reduction. The Catell's Scree test and parallel analysis as recommended by (Costello \& Osborne, 2005; Hayton, J. et al, 2004) and the interpretability criteria were used in deciding on the number of meaningful 
components to be retained. A given component is retained if it has a factor loading of at least 0.40 (Stevens, 1986) and items that load to more than one component are candidates for deletion. An item that does not load to any component is also a candidate for deletion. Cronbach alpha was used to determine the internal consistency of the revised DREEM instrument. An item has an acceptable level of internal consistency if its Cronbach alpha is at least 0.70 (Nunally, 1978; Streimer \& Norman, 2008). An item is considered to contribute highly to the construct being measured if its corrected item-total correlation has a value of more than 0.3 (Yusoff et al., 2010).

\subsection{Results}

3.1 Principal Component Analysis

Out of the 398 practice teachers who completed the revised DREEM only 316 data sets were used in the analysis because questionnaires with missing cases were excluded. There were 82 missing cases spread through 42 out of the 50 items in the scale. Results of the Kaiser-Meyer-Olkin (KMO) sampling adequacy measure was 0.846 while Bartlett's Test for Sphericity was 4848.007, significant $(p \leq 0.001)$. These results confirmed that the data set was suitable for principal component analysis. The scree plot showed a sharp point of inflection after the first component (Figure 1) and started to level off after the fifth, suggesting 5 subscales.

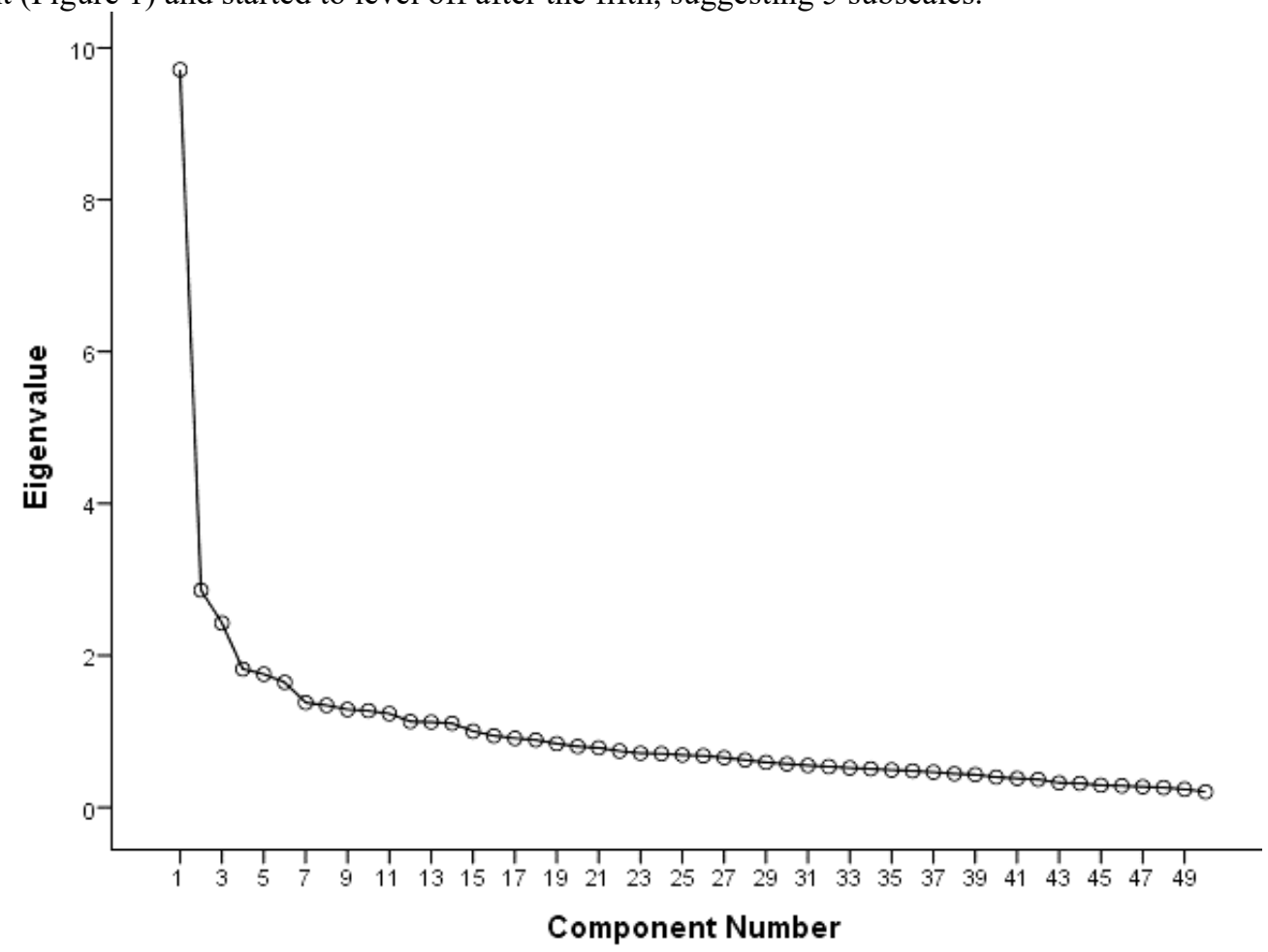

Figure 1. Scree plot of the eigenvalues of the components of the modified DREEM scale.

Moreover, the result of the parallel analysis (Table 1) shows that there are five components from the actual data whose eigenvalues exceeded the $95^{\text {th }}$ percentile eigenvalues. The scree plot and parallel analysis results were the bases for retaining number of meaningful components. After the rotation, components 1 to 5 accounted for a total variance of $39.59 \%$.

Table 1. Raw data eigenvalues, \& mean \& percentile random data eigenvalues

\begin{tabular}{cccc}
\hline Root & Actual Data & Means & $95^{\text {th }}$ Percentile \\
\hline 1.000000 & 10.515830 & 1.954539 & 2.053394 \\
2.000000 & 2.928466 & 1.856758 & 1.926680 \\
3.000000 & 2.640122 & 1.781992 & 1.844449 \\
4.000000 & 1.942142 & 1.719153 & 1.773483 \\
5.000000 & 1.766481 & 1.661791 & 1.713667 \\
6.000000 & 1.647092 & 1.610776 & 1.657045 \\
7.000000 & 1.421716 & 1.561550 & 1.607706 \\
8.000000 & 1.390811 & 1.516328 & 1.560134 \\
9.000000 & 1.312748 & 1.473280 & 1.511614 \\
10.000000 & 1.277776 & 1.432270 & 1.471553 \\
\hline
\end{tabular}

Based on the criteria set for item retention, the first component consisted of items 29, 37, 40, 2, 18, 6, 3, 32 and 1 refers to students' perception of their cooperating teachers. The second component contained items 10, 22, 
$16,45,13,31,30,12,20$ and 15 . These items are about students' perception of teaching. Items $23,11,34$, and 24 made up the third component which refers to students' perception of atmosphere. The fourth component consisted of items 28, 21, 41, 27, 42, 47, 14 and 43 describes students' perception of learning. Finally, the fifth component refers to negative perception of cooperating teachers and teaching consists of items 35, 39, 9, 8, 4, 50 and 48 . Further analysis show that items 5, 7, 17, 19, 25, 26, 33, 36, 38, 44, 46 and 49 have loadings which are less than .40, hence these were deleted. Component loadings ranged from .40 to .722 . Table 2 presents the rotated component loadings of the modified DREEM instrument. Italicized items were excluded from the final form of the scale.

Table 2. Items and rotated component loadings of the adapted DREEM scale.

\begin{tabular}{|c|c|c|c|c|c|c|}
\hline \multirow[t]{2}{*}{ No. } & \multirow[t]{2}{*}{ Item } & \multicolumn{5}{|c|}{ Component } \\
\hline & & 1 & 2 & 3 & 4 & 5 \\
\hline 29 & The teachers are good at providing feedback to students. & .702 & & & & \\
\hline 37 & The teachers give clear examples. & .691 & & & & \\
\hline 40 & The teachers are well prepared for their classes. & 640 & & & & \\
\hline 2 & The teachers are knowledgeable. & .631 & & & & \\
\hline 18 & The teachers have good communications skills. & .602 & & & & \\
\hline 6 & The teachers are patient with students. & .592 & & & & \\
\hline 3 & There is a good support system for students who get stressed. & .499 & & & & \\
\hline 32 & The teachers provide constructive criticism. & .449 & & & & \\
\hline 1 & I am encouraged to participate in class. & .443 & & & & \\
\hline 46 & My accommodation is pleasant. & & & & & \\
\hline 49 & I feel able to ask the questions I want. & & & & & \\
\hline 10 & I am confident about my passing this year. & & 679 & & & \\
\hline 22 & $\begin{array}{l}\text { The teaching is sufficiently concerned to develop my } \\
\text { confidence. }\end{array}$ & & .605 & & & \\
\hline 16 & $\begin{array}{l}\text { The teaching is sufficiently concerned to develop my } \\
\text { competence. }\end{array}$ & & .556 & & & \\
\hline 45 & $\begin{array}{l}\text { Much of what I have to learned seems relevant to my career } \\
\text { in teaching. }\end{array}$ & & .535 & & & \\
\hline 13 & The teaching is student-centered. & & .492 & & & \\
\hline 31 & I have learned a lot about empathy in my profession. & & .472 & & & \\
\hline 30 & $\begin{array}{l}\text { There are opportunities for me to develop interpersonal } \\
\text { skills. }\end{array}$ & .405 & .469 & & & \\
\hline 12 & This school is well time-tabled. & & .457 & & & \\
\hline 20 & The teaching is well focused. & & .404 & & & \\
\hline 15 & I have good friends in this school. & & .402 & & & \\
\hline 5 & $\begin{array}{l}\text { Learning strategies which worked for me before continue to } \\
\text { work for me now. }\end{array}$ & & & & & \\
\hline 19 & My social life is good. & & & & & \\
\hline 44 & The teaching encourages me to be an active learner. & & & & & \\
\hline 23 & The atmosphere is relaxed during lectures. & & & .722 & & \\
\hline 11 & The atmosphere is relaxed during the practice teaching. & & & 699 & & \\
\hline 34 & The atmosphere is relaxed during seminars/tutorials. & & & .665 & & \\
\hline 24 & The teaching time is put to good use. & & & .432 & & \\
\hline 26 & $\begin{array}{l}\text { Last year's work has been a good preparation for this year's } \\
\text { work. }\end{array}$ & & & & & \\
\hline 25 & The teaching over-emphasizes factual learning. & & & & & \\
\hline 33 & I feel comfortable in class socially. & & & & & \\
\hline 28 & I seldom feel lonely. & & & & .515 & \\
\hline 21 & I feel I am being well prepared for my profession. & & & & .503 & \\
\hline 41 & My problem-solving skills are being well developed here. & & & & .471 & \\
\hline 27 & I am able to memorize all I need. & & & & .463 & \\
\hline 42 & The enjoyment outweighs the stress of the course. & & & & .459 & \\
\hline 47 & Long term learning emphasizes over short term. & & & & .450 & \\
\hline 14 & I am rarely bored on this course. & & & & .437 & \\
\hline 43 & The atmosphere motivates me as a learner. & & & & .431 & \\
\hline 36 & I am able to concentrate well. & & & & & \\
\hline 35 & I find the experience disappointing. & & & & & .672 \\
\hline 39 & The teachers get angry in class. & & & & & .660 \\
\hline 9 & The teachers are authoritarian. & & & & & .589 \\
\hline
\end{tabular}




\begin{tabular}{|c|c|c|c|c|c|c|}
\hline \multirow[t]{2}{*}{ No. } & \multirow[t]{2}{*}{ Item } & \multicolumn{5}{|c|}{ Component } \\
\hline & & 1 & 2 & 3 & 4 & 5 \\
\hline 8 & The teachers ridicule the students. & & & & & .536 \\
\hline 4 & I am too tired to enjoy the course. & & & & & .423 \\
\hline 50 & The students irritate the teachers. & & & & & .411 \\
\hline 48 & The teaching is too teacher-centered. & & & & & .409 \\
\hline 17 & Cheating is a problem in this school & & & & & \\
\hline 38 & I am clear about the learning objectives of the course. & & & & & \\
\hline 7 & The teaching is often simulating. & & & & & \\
\hline
\end{tabular}

Further examination of the individual items whose component loadings were .40 and above, revealed that some items loaded to a component with different conceptual meaning. For instance item 3 (There is a good support system for students who get stressed) and item 1 (I am encouraged to participate in class) loaded to component 1 (perception of cooperating teachers). Similarly, item 15 (I have good friends in this school) loaded to component 2 (students' perception of teaching). Item 30 (There are opportunities for me to develop interpersonal skills) loaded to component 1 (perception of cooperating teachers) and component 2 (perception of teaching). These items also did not pass the criteria for inclusion in the final item grouping of the instrument. A total of 17 items were eliminated reducing the modified DREEM instrument to 33 items. The final item grouping is presented in table 3. The subscales of the shortened instrument are labeled as: perception of teachers, perception of teaching, perception of atmosphere, perception of learning, and negative perception of teachers and teaching.

Table 3. Items of the final dimensions and alpha values of each item of the shortened DREEM scale for assessing practice teaching environment.

\begin{tabular}{|c|c|c|}
\hline Item No. & Perception of Cooperating Teachers & $\begin{array}{l}\text { Cronbach's Alpha if } \\
\text { Item Deleted }\end{array}$ \\
\hline 29 & The teachers are good at providing feedback to students. & .829 \\
\hline 37 & The teachers give clear examples. & .831 \\
\hline 40 & The teachers are well prepared for their classes. & .825 \\
\hline 2 & The teachers are knowledgeable. & .834 \\
\hline 18 & The teachers have good communications skills with students. & .836 \\
\hline 6 & The teachers are patient with students. & .829 \\
\hline \multirow{2}{*}{\multicolumn{3}{|c|}{$\begin{array}{l}\text { The teachers provide constructive criticism. } \\
\text { Perception of Teaching }\end{array}$}} \\
\hline & & \\
\hline 10 & I am confident about my passing this year. & .829 \\
\hline 22 & The teaching is sufficiently concerned to develop my confidence. & .827 \\
\hline 16 & The teaching is sufficiently concerned to develop my competence. & .850 \\
\hline 45 & Much of what I have to learned seems relevant to my career in teaching. & .829 \\
\hline 13 & The teaching is student-centered. & .825 \\
\hline 31 & I have learned a lot about empathy in my profession. & .825 \\
\hline 12 & This school is well time-tabled. & .826 \\
\hline 20 & The teaching is well focused. & .825 \\
\hline Item No. & Perception of Atmosphere & \\
\hline 23 & The atmosphere is relaxed during lectures. & .827 \\
\hline 11 & The atmosphere is relaxed during the practice teaching. & .827 \\
\hline 34 & The atmosphere is relaxed during seminars/tutorials. & .830 \\
\hline 24 & The teaching time is put to good use. & .824 \\
\hline \multicolumn{3}{|c|}{ Perception of learning } \\
\hline 21 & I feel I am being well prepared for my profession. & .825 \\
\hline 41 & My problem-solving skills are being well developed here. & .827 \\
\hline 27 & I am able to memorize all I need. & .830 \\
\hline 42 & The enjoyment outweighs the stress of the course. & .826 \\
\hline 47 & Long term learning emphasizes over short term. & .823 \\
\hline 14 & I am rarely bored on this course. & .826 \\
\hline 43 & The atmosphere motivates me as a learner. & .824 \\
\hline \multicolumn{3}{|c|}{ Negative Perception of Teachers and Teaching } \\
\hline 35 & I find the experience disappointing. & .825 \\
\hline 39 & The teachers get angry in class. & .826 \\
\hline 9 & The teachers are authoritarian. & .824 \\
\hline 8 & The teachers ridicule the students. & .825 \\
\hline 4 & I am too tired to enjoy the course. & .828 \\
\hline 50 & The students irritate the teachers. & .839 \\
\hline 48 & The teaching is too teacher-centered. & .832 \\
\hline
\end{tabular}




\subsection{Reliability Analysis}

Three internal consistency analysis were done for this study. The first was the overall Cronbach alpha of the modified 50 - item DREEM scale, second was the analysis done for the shortened DREEM and the reliability analyses for each of the subscales of the shortened instrument. Results show that the Cronbach alpha of the modified DREEM and the shortened DREEM were 0.86 and 0.83 respectively and the subscale reliability analysis resulted to Cronbach alphas ranging from 0.71 to 0.80 .

Table 4. Internal consistency coefficients of the subscales of the shortened DREEM scale

\begin{tabular}{lc}
\hline Subscale & Cronbach $\alpha$ \\
\hline Perception of Teachers & .80 \\
Perception of Teaching & .76 \\
Perception of Atmosphere & .73 \\
Perception of Learning & .71 \\
Negative Perception of Teachers and Teaching & .76 \\
Overall alpha & .83 \\
\hline
\end{tabular}

\subsection{Discussion}

The aim of the current study was to adapt and establish the validity and reliability of the DREEM scale in a sample of practice teachers from a state university in the Philippines. To explore the underlying structure of the adapted DREEM, a principal component analysis with Varimax rotation was performed using the data set gathered from 316 practice teachers. Result of the parallel analysis was used in deciding the number of components retained in the final form of the scale since it is considered as the most accurate technique as recommended by Ledesma \& Valero - Mora (2007). The result of this study did support the five-component structure of original DREEM instrument, however, loading of the items to specific components were inconsistent with the original loading. For instance, the components academic self-perceptions and social self-perceptions were not identified in this study, instead

For instance, in the original DREEM, the components are perception of learning, perception of teachers, academic self-perceptions, perceptions of atmosphere and social self-perceptions, in this study, component are named as perception of teachers, perception of teaching, perception of atmosphere, perception of learning and negative perception of teaching and teachers while in this study, the five comp perceptions of cooperating teachers, perception of teaching, perception of atmosphere, perception of learning and negative perception of teaching and teachers. These findings are consistent with results reported by (Schonrock-Adema 2009; Khan et al. 2011; Jakobson et al. 2011; Yusoff 2012; Hammond et al. 2012; Vaughan et al. 2014; Mogre \& Amalba, 2016; Leman 2017;). As has been suggested by the previous studies, removal of specific items might improve the goodness of fit of the five-factor structure (Dimoliatis et al., 2010; Hammond et al., 2012;). The mismatch in the item loadings and subscales between the original and the shortened DREEM may be attributed to disparity of the environments and samples where the study took place. The original DREEM was intended for medical environments and medical undergraduate students while in the current study the environment are the laboratory schools where practice teaching is done and students are teacher education students. After eliminating items that did not satisfy the interpretability criteria, although retaining the original five subscales the instrument was reduced to 33 with the following proposed subscales: Perception of Cooperating Teachers, Perception of Teaching, Perceptions of Atmosphere, Perception Learning and Negative Perception of Teachers and Teaching.

Reliability analyses for both adapted and shortened version of the DREEM resulted to items with acceptable internal consistency. Similarly, its subscales have acceptable Cronbach alpha values which are acceptable. These values show that the five dimension of the shortened instrument also contain items with acceptable internal consistency.

There are some limitations of this study. First, the student teaching program is typically divided into shifts consisting of the on campus and off-campus shifts. These students while undergoing the student teaching program are assigned to different learning environments, the cooperating schools for the off-campus shift and the laboratory school in the university for the in-campus shift. It is possible that they were confused as to which of the in-campus or off-campus learning environment they should assess hence the mismatch in item loading with the original instrument. The sample size in this study could also be an issue considering that there were only 316 respondents, short of the ten respondents per item as suggested by Costello \& Osborne (2005).

\subsection{Conclusion}

This study did support the five-component structure of the DREEM, however, loadings of items to the five dimensions in the shortened version were inconsistent with the original DREEM. With minor modifications of some items which seem to have different conceptual meaning from the rest and considering that the items in each subscale have reasonably good internal consistency indices, the shortened version may be use to assess practice teachers' perception of their learning environment. The shortened instrument will be called as Practice Teachers' 
Education Environment Measure.

\section{References:}

Ambag, Silvia C. Assessment of competency level of pre-service teachers based on national competency-based teacher standards (NCBTS) in public schools in the national capital region (NCR) European Academic Research Vol. II, Issue 11/ February 2015

Bakhshialiabad, H., Bakhshi, M., \& Hassanshahi, G. (2015). Students' perceptions of the academic learning environment in seven medical sciences courses based on DREEM. Advances in medical education and practice, 6, 195.

Barcelo, J. M. (2016). Medical laboratory science and nursing students' perception of academic learning environment in a Philippine university using Dundee Ready Educational Environment Measure (DREEM). Journal of Educational Evaluation for Health Professions, 13.

Bay Jr, B. E., \& Subido, H. (2014). DREEM is real: dental students learning environment in an asian university. International Journal of Academic Research in Business and Social Sciences, 4(7), 620.

Brown, T., Williams, B., \& Lynch, M. (2011). The Australian DREEM: evaluating student perceptions of academic learning environments within eight health science courses. International Journal of Medical Education, 2, 94

Costello, A. B., \& Osborne, J. W. (2005). Best practices in exploratory factor analysis: Four \recommendations for getting the most from your analysis. Practical assessment, research \& evaluation, 10(7), 1-9.

Dahar, M. A., Dahar, R. T., \& Dahar, R. A. (2009). Impact of the prior school environment on academic achievement of students at the secondary stage in Punjab (Pakistan). Munich Personal RePEc Archive

Dimoliatis, I. D., Vasilaki, E., Anastassopoulos, P., Ioannidis, J. P., \& Roff, S. (2010). Validation of the Greek translation of the Dundee ready education environment measure (DREEM). Education for Health, 23(1), 348.

Dunteman, G. H. (1989). Principal component analysis (Quantitative applications in the social sciences). Thousand Oaks, CA: Sage

Ganal, N. N., Andaya, O. J. F., \& Guiab, M. R. Problems and difficulties encountered by student teachers of Philippine Normal University, Isabela Campus

Kamaruddin, R., Zainal, N. R., Aminuddin, Z. M., \& Jusoff, K. (2009). The quality of learning environment and academic performance from a student's perception. International Journal of Business and Management, 4(4), 171.

Khursheed, I., \& Baig, L. (2014). Students' perceptions of educational environment of a private medical school in Pakistan. J Pak Med Assoc, 64(11), 1244-1249.

Hamid, B., Faroukh, A., \& Mohammadhosein, B. (2013). Nursing students' perceptions of their educational environment based on DREEM model in an Iranian university.

Hammond, S. M., O’Rourke, M., Kelly, M., Bennett, D., \& O’Flynn, S. (2012). A psychometric appraisal of the DREEM. BMC medical education, 12(1), 1.

Hayton, J. C., Allen, D. G., \& Scarpello, V. (2004). Factor retention decisions in exploratory factor analysis: A tutorial on parallel analysis. Organizational research methods, 7(2), 191- 205.

Jakobsson, U., Danielsen, N., \& Edgren, G. (2011). Psychometric evaluation of the Dundee ready educational environment measure: Swedish version. Medical Teacher, 33(5), e267-e274.

Kellow, J. T. (2007). Using principal components analysis in program evaluation: some practical considerations. Journal of Multi Disciplinary Evaluation, 3(5), 89-107.

Ledesma, R. D., \& Valero-Mora, P. (2007). Determining the number of factors to retain in EFA: An easy-to-use computer program for carrying out parallel analysis. Practical assessment, research \& evaluation, 12(2), 111.

Lizzio, A., Wilson, K., \& Simons, R. (2002). University students' perceptions of the learning environment and academic outcomes: implications for theory and practice. Studies in Higher education, 27(1), 27-52.

Miles, S., Swift, L., \& Leinster, S. J. (2012). The dundee ready education environment measure (DREEM): a review of its adoption and use. Medical teacher, 34(9), e620-e634.

Mogre, V., \& Amalba, A. (2016). Psychometric properties of the dundee ready educational environment measure in a sample of Ghanaian medical students. Education for Health, 29(1), 16.

Riga, V., Kossioni, A., \& Lyrakos, G. (2015). Can DREEM instrument (Dundee Ready Education Environment Measure) measure the learning environment in a school of education?. Educational Journal of the University of Patras UNESCO Chair.

Roff, S., McAleer, S., Harden, R. M., Al-Qahtani, M., Ahmed, A. U., Deza, H., ... \& Primparyon, P. (1997). Development and validation of the Dundee ready

education environment measure (DREEM). Medical teacher, 19(4), 295-299.

Patil, A. A., \& Chaudhari, V. L. (2016). Students' perception of the educational environment in medical college: a study based on DREEM questionnaire. Korean Journal of Medical Education, 28(3), 281 
Schönrock-Adema, J., Heijne-Penninga, M., van Hell, E. A., \& Cohen-Schotanus, J. (2009). Necessary steps in factor analysis: enhancing validation studies of educational instruments. The PHEEM applied to clerks as an example. Medical Teacher, 31(6), e226-e232.

Thapa, A., Cohen, J., Guffey, S., \& Higgins-D’Alessandro, A. (2013). A review of school climate research. Review of Educational Research, 83(3), 357-385.

Usaini, M. I., Abubakar, N. B., \& Bichi, A. A. (2015). Influence of school environment on academic performance of secondary school students in Kuala Terengganu, Malaysia. The American Journal of Innovative Research and Applied Sciences, 1(6), 203. 